\title{
Networked technologies and other stories: New paradigms for learning
}

\author{
Alnaaz Kassam \\ 8 Burnt Bark Dr., Scarborough Canada.
}

\begin{abstract}
This paper examines the role of networked technologies in transforming education from a teacher-centred, text-book driven and mono-cultural world view within one classroom to learning across national borders, where students become investigators, thinkers and knowledge creators reflecting upon the problems of the world. This papers reports on a research project which linked Canadian students with experts to study diverse cultures of the world. Through the research study, it was discovered that achieving a reflective approach to studying "others" is not merely a matter of breaking classroom walls and making contact, but rather includes changing attitudes and acquiring an ability to approach knowledge in a more constructivist manner.
\end{abstract}

Keywords: Internet, inter-cultural understanding, constructivist learning

\section{BACKGROUND}

A few years ago, an IBM ad on TV showed a group of nuns discussing the latest program from IBM. "I just read about it in Wired," explains one nun. "You get true multitasking and easy access to the Internet" to which the Mother Superior replies: "I'm dying to surf the Net" The picture fades as the pager tucked under her habit starts to beep.

Another ad for the IBM Aptiva portrayed Africa - the computer stood in the middle of a lush field. A choir practised a song and was unable to find the right musical note on which to begin singing. A child playing some music software on the nearby computer, gives them the right note. The choir breaks into happy smiles, singing again. 
What is the symbolism here? We see Africa as it is always portrayed happy, smiling people, its countryside, no sight of the complex, cosmopolitan cities, Africans singing. We see also that it takes a child on a foreign computer to find the solution to a simple problem - a problem that surely any African is infinitely more capable of solving than a computer. These ads formed part of a series that was running on TV - ads that presented people from varied cultures, varied occupations and distant countries - all relying on the technology and the support that IBM provides.

What did these advertisements portray? From the point of IBM they portrayed access. They portrayed technology that is accessible both geographically but also across cultural, social, ethnic, national and even religious boundaries. And it is a theme that is echoed throughout the literature on the Internet - whether in the arts, business or education. The underlying message around all the promotion attempts is: the Internet will provide access to information, to communication and to dissemination. Without it, you will be left behind. You will not be able to participate. At the same time, the ads seem to proudly proclaim that all people - regardless of national, cultural, racial or even physical ability can participate in, benefit and access the new technology. But is the phenomenon we just described access? Is it access when those being portrayed do not own, produce nor direct their own portrayal?

Porter (1994) would argue that the medium of television and its ads belonged to the older broadcast model of media where a small number of producers sent information to a large number of consumers. However with the new computer networks, this is changing In fact, with the information highway and the integration of satellite technology with television, computers and the telephone, the broadcast model will change to a system with multiple producers, distributors and consumers.

In the new media age that Porter describes, Africans could participate in conveying their own views of themselves - but if Africans can, so can all the cultures of the world. However, what is even more frightening in its power, is the potential for everyone - including our students to join in the fray. When this technology moves into the traditional teacher-centred, text-book driven classroom, knowledge dissemination has to change too. Eurich-Fulcer and Schofield (1995) explain that WAN technologies challenge the transmission mode of knowledge as facts to one where knowledge is based on individuals' perspectives and opinions. According to them, students will have to evaluate information, rather than simply absorb facts.

For Cummins and Sayers (1995), the root of the problem is the mismatch between industrial and post-industrial organisation of society, wherein students need to be perceived as autonomous beings who will use technology in a process of critical collaborative inquiry. 
Similarly, Keating (1995) explains, we are in the midst of a technological change that will demand a transformation in societal functioning. This transformation is arising from already existing information technology that includes instantaneous global communication, unlimited knowledge storage and retrieval, sophisticated data analysis and simulation along with artificial intelligence that includes robotic manufacture.

Keating (1995) in this context, describes the transformation of society in the information age (as opposed to the industrial age) as being one where:

- pedagogy moves from knowledge transmission to knowledge building;

- the prime mode of learning being individual to one where it becomes more collaborative;

- where educational goals geared toward conceptual grasp for the few and basic skills and algorithms for the many, move to conceptual grasp and intentional knowledge building for all;

- there is a developmental model of life-long learning for everyone not just for an elite;

- vertical bureaucracies are replaced by collaborative learning organisations.

And in the kind of Internet projects described by Riel (1996), we can see that new learning provides for forms of integration very different from reading a text, watching a video or listening to a teacher speak. Students can interact with exhibits in a museum, take a walk through the White House, aim a telescope out into space, dissect a frog, take a stroll through a zoo and visit cities around the world. For Riel these connections are possible when we accept the Internet not as a physical context but an evolving social construction - when one accepts that it is not technology but people that form communities. Similarly, in the building of Internet networks, it is not the technology that will build relations but rather the social connections and constructions that will form the communities.

But it is not merely through social contact and the building of communities that one acquires true inter-cultural understanding. This is achieved through a change in attitudes and engendering in students an ability to carry out critical inquiry and the collaborative creation of knowledge through dialogue in their classrooms and with classrooms across the globe. This is not achieved through a passive acquisition of facts or even complex literary styles or historical analysis in the cultural literacy of socially powerful groups. (Cummins \& Sayers, , 1995, p. 13). For Cummins and Sayers (1995, p. 170), it is a pedagogy of collaborative critical inquiry which will make schooling relevant to marginalised populations of students and engage them in academic effort. This pedagogy is achieved through fostering students' ability to think critically about complex social issues and take collective action to shape their societies (Cummins \& Sayers, 1995, p. 170). 
In fact, as this paper will demonstrate, one can break down classroom walls, one can change knowledge from a top-down to a collaborative model, one can bring in the perspectives of less dominant peoples into the classroom but none of these will affect attitudes and ways of critically approaching issues. These aspects of human development go beyond technology.

\section{THE NEED FOR INTER-CULTURAL UNDERSTANDING IN THE GLOBAL CONTEXT}

It is clear that as we enter the new millennium, global relations between peoples of the developing and developed world will become more and more frequent. In this context, inter-cultural understanding between peoples of the world becomes critical. As Cummins and Sayers (1995, p. 10) explain, Marshall McLuhan's "global village" is upon us. There is unprecedented inter-cultural contact globally resulting from a variety of factors: economic and political migration, technological advances in transportation and telecommunication, economic and political interdependence between countries of the world etc. This increasing inter-cultural contact both within and without national borders cries out for more two-way communication between cultures and an understanding of divergent cultural perspectives.

\section{INTER-CULTURAL UNDERSTANDING AND THE OTHER STORY PROJECT}

The paper reports the results of a research project entitled: The Other Story: Research in the Development of Telecommunications Materials to Promote Inter-cultural Understanding. The Ontario Ministry of Education and Training funded the project for two years. The Principal Investigator of the project was the author of this paper. Co-Investigators Dr. Rina Cohen and Dr. Brian Durell participated in the project. There were 3 on line conferences during this time, two explored issues of the impact of the TV on the Caribbean region and one looked at Canadian history from both a First Nations perspective and the traditional text book version.

The main objective of the Other Story project was to bring the "Other" into the classroom through the Internet. The first episode of the project (on which this paper reports) involved linking students in the Caribbean and in Canada through an online virtual conference. The conference participants also included a teacher and Canadian students of Caribbean origin, as well as experts in various aspects of Caribbean culture. All online data was captured 
and analysed. Most classrooms were also observed by trained researchers. The project was further enhanced by in-depth teacher interviews.

The project brought issues of social justice, cultural survival and the fair portrayal of all cultural, social and national groups into the classroom. The project's first premise was that the people whom we studied would create the materials that were developed and distributed in schools.

The project was carried out in the form of a simulation with each classroom posing as the government of a fictitious Caribbean island. Each government was posed with the task of debating whether they wanted to regulate TV on their island or not. Each classroom was divided into 4 groups representing the Ministries of Culture, Tourism, Finance and Information. Each Minister received a portfolio of materials relating to the Ministry.

The Other Story was a program that introduced students to the rest of the world from an "issue-centred" perspective. When students debated the issue of the impact of global TV on the Caribbean, the Ministers of Tourism read amongst other things, the work of Jamaica Kincaid, who describes one aspect of tourism in her home of Antigua in the following way:

"The word 'emancipation' is used so frequently, it is as if it, emancipation, were a contemporary occurrence, something everyone is familiar with. And perhaps there is something in that, for an institution that is often celebrated in Antigua is the Hotel Training School, a school that teaches Antiguans how to be good servants, how to be a good nobody, which is what a good servant is. In Antigua, people cannot see a relationship between their obsession with slavery and emancipation and their celebration of the Hotel Training School (graduation ceremonies are broadcast on radio and television)."

Students also read an article on tourism which gave figures of how much of the tourist dollar is already spent in the tourist's home country towards the airline ticket. Often the hotel where the tourist stays, is owned by the airline and the food consumed by the tourist during his visit is bought overseas, before the tourist even gets to the Caribbean.

The students correspondingly watched a film called The Dish Ran Away with the Spoon. The is part of a series on issues of development put out by the BBC. It explores the issue of cultural domination and TV through the perspective of the people affected: artists, writers, teachers, religious leaders, politicians, school children and other ordinary people.

In this film, the director visits Cuba and laments its poverty but then feels that at least the Cubans have been able to keep their culture, whereas, he on his own island is bombarded with images of snowy weather forecasts on $\mathrm{CNN}$ and episodes of an afternoon soap opera. The film also interviews a 
priest who is trying to ensure that the cultural heritage of his people is preserved through music, dance and drama.

Students also read stories, poems, commentary and newspaper articles on the Caribbean region. Students as part of the conference that was held on a listserv on Schoolnet, a Canadian educational online network, also had the opportunity to pose questions to members of the Caribbean culture who were available online and who offered comments to students. A classroom in Barbados was also linked to the project.

All Canadian schools in the project were inner-city schools with students from working class neighbourhoods. Students, in classroom observations, carried out before the project commenced, tended to be apathetic, uninterested in school and classroom discussions. An interview with one classroom teacher, Keith, revealed that he was depressed by the apathy and disinterest of his students. He had tried everything, including having students watch films on social and economic inequities, classroom discussions on everyday life, even career discussions. Students were in their last year in school, ready to join the workforce as soon as the semester was over and school was largely irrelevant to them.

\section{INTER-CULTURAL UNDERSTANDING}

The materials provided the students with online conference experience and the online presence of the Caribbean experts were carefully selected for authenticity, wisdom and a true reflection of the culture. The researchers were not prepared for the extreme racism and narrow-minded views of the students who formed part of the conference.

\subsection{Incident 1: the Caribbean as a resort}

Amongst the first comments to emerge online were students' preconference impressions of the Caribbean.

"The Caribbean gives me a lot of different impressions. For example, Jamaica. When I think of Jamaica I think of holidays, honeymoons, sun, fun and sand. Also I think that the people would be very happy (high), because marijuana is legalised."

In one class, the teacher lists comments from students on the board:

"Goats and pigs running around, surfing, people living in grass huts on beaches, street markets, low paying jobs, no electricity, nude beaches, cruise ships, dreadlocks (hair style), alcohol, tropical storms, tropical 
fruit, say 'Hey man' (like we say 'eh'), black, bare footed people, dress in grass skirts, colourful clothes, hot/nice weather, seafood, parties, sun tanning, drug problems, reggae, lots of tourism, sandals."

In this example, we see illustration of the typical stereotypical views of the Caribbean, which are by no means isolated.

Why would Canadian students have these images of the Caribbean? A research report, which analysed the portrayal of minorities in Canada, showed that in general they are under-represented among the newsmakers, experts and citizens presented by the news media. Where attention is received in the media, minorities are portrayed as villains and victims than as newsmakers, experts reacting to contemporary events (Ungerleider, 1991).

Television ads, especially during the harsh winter months, show swimsuit clad white couples frolicking on beaches that have deep blue water and pure white sand. Black waiters in impeccable white suits carry trays of delectable fruit drinks to white women lounging on deck chairs by the swimming pool. The ads are invariably accompanied by loud music from the Caribbean.

And as we observed above, this portrayal of the Caribbean is not so very different from the portrayal of Africa, a model of media dissemination that is reminiscent of the older broadcast model of TV. It does not encourage questioning, nor a discussion of issues.

\subsection{Incident 2: The Caribbean as a third world country}

Later in the same day, the researcher in Keith's classroom observes the following conversation:

Student 1: "Let us discuss the other responses from the other classes to see what is realistic and logical."

Student 2: "Did you watch the American music awards the other night, it was neat."

Student 3: "The video we watched on the Caribbean was propaganda: they only focused on the problems of a little TV."

Student 2: "I think they are lucky to have TV: some people cannot even afford to eat."

Student 3: "I have been there, they live in shacks and don't have TV."

Student 2 says: "What do we write, we just need one response." and writes: "I think they are lucky to have TV. Some people cannot even afford to eat."

Student 2: "We have finished." 
An online quotation from another school reflects similar patronising attitudes and disdain for the Caribbean. When asked if watching the video has changed his mind about the Caribbean, the student replies:

"My impression of the Caribbean has not changed because I found the video to be somewhat unrealistic. I have been to the Dominican Republic and saw what it was really like, I mean I actually went out of the American resort that I was staying at and looked around. I visited the market and the beach and the mountains. The video portrayed the Caribbean as this great place where everyone is happy and only worried about what the children watch on TV when they are lucky to even have a TV."

Here once again we see the deep ignorance of the response, the idea that the Caribbean people are so poor that they have no right to complain about TV and its domination of their culture. They should be happy that they have a roof over their heads. It is an attitude that is both arrogant and simplistic.

\subsection{Incident 3: The Caribbean as poor}

Our final excerpt from the Other Story research project is the following comment placed on the listserv right at the beginning of the conference by a young female student who has been to the Caribbean:

"The images that come to my mind when I think of Caribbean culture is hot weather and a third world place. I think of people living in plastic tents on the beach, eating the hard fruits that fall from the trees. During the day they spend all their time making little boxes and braiding the tourists' hair. The tourists barter with them and cheat them of their profit. The people of the Caribbean know this so they raise the price sometimes by a couple hundred pesos. A golden coloured pendant is almost never real gold. The people are so desperate to sell that they carve $14 \mathrm{k}$ into the bottom and fool all the tourists. The children are made to work from whenever they can walk and talk until they can no longer work, their children will now take care of them. The schools are very expensive so no one goes. All the money that the tourists spend at the resort goes to the United States. None of the tourism money goes to the people. Not many of the people have real paying jobs and those few who get picked to work in a rum factory earn less than 20.00 American dollars a month. Most of them even have a big family to support." 
From this excerpt can be observed the stereotypes of the developing world. People living in plastic tents on the beach, poverty, people cheating on tourists, too many children and child labour.

We also see that a certain view of the Caribbean is emerging, a view that reflects the environment of the North American attitude of superiority, of ignorance of the rest of the world. At the same time, there is a flaunting of that ignorance. This is the perspective that will be observed in almost mirrorlike reflection in the popular films that will be discussed below.

In the next section these three incidents will be analysed to demonstrate how the virtual networking aspect of the simulation permitted the exposure of different views, more complex analysis and most importantly, the perspective of the members of the culture which was being studied.

\section{THE INTERNET'S ADVANTAGE FOR INTER- CULTURAL UNDERSTANDING}

The above section demonstrated quite adequately that students in the classes were quite ignorant of the Caribbean, had succumbed to stereotypical views and were totally influenced by the tourist image of the Caribbean as a beautiful but primitive place to visit.

In this section the interactivity of the listserv will be displayed. This was a conference that insisted on the presence of members of the Caribbean community, both as students and as "experts". This resulted in other images of the Caribbean emerging. This perspective would have proved impossible, had students only had access to textual or video material, especially if these materials did not reflect the cultures that they proposed to study, which is what occurs in most cases. However, as seen in the above incidents, while the technology brought in different perspectives and allowed an issueoriented perspective, students were for the most part passive, interested only in the most superficial of discussions.

ICT cannot change approach to learning, only schools or teachers can contribute toward this process. ICT can certainly facilitate that process by providing resources in the form of text and visual resources, linkages between peoples of different cultures, but as Riel pointed out earlier, the building of social relationships, the building of human communities is the work of human beings. And as Cummins and Sayers (1995) also concluded, inter-cultural understanding must be based on critical collaborative inquiry. We shall discuss the power of ICT within this context. 


\subsection{Analysis of Incident 1}

The following is the response of the students from a school in Barbados, who are reacting to the comments from students about their pre-conference perceptions of the Caribbean as a primitive but "paradise-like" place to visit.

"One of the misconceptions about the Caribbean is that the people live in grass huts on beaches and that there are goats and pigs running wild. This is in no way accurate. Caribbean people live in regular wood or brick houses just like everyone else and like most people we build pens and sties for our goats and pigs, if we have any. Considering that we live in regular houses, it is safe to assume that we have electricity and running water.

"Freedom is very important to Caribbean people. We are not thrown into prison for giving our opinions on political matters, neither is the press under the control and direction of the government. Barbados is very politically stable. Our parliament has been in existence for over 350 years. We experience much less crime and drug use than urban societies in Canada and the U.S.A.

"Tourism is also important to the Caribbean but the images which people are given about the Caribbean create their own misconceptions. The tourists are led to believe that tropical life is one long party but the truth is that it is not. There is more to these islands than tourism. We are real people with real problems."

Here we see that the Internet provides, over the quick images of TV and of the stories created in movies, voice. The interactivity of the listserv brought the views of people (students just like the ones in Canada) actually living in the Caribbean to challenge the stereotypical views that were thrown at them. Thus the first advantage of the Internet for education in intercultural understanding is that it provides interactivity.

Secondly, because the interactivity is available to everyone who is a node on a network, it is a level playing field and so Internet provides equality between participants. It is important to note that the school in Barbados is a high-cost school which promotes high academic skills and university entrance. It is not a school which has technology, but it is not the technology which promotes higher thinking skills and critical collaborative inquiry but rather the approach to constructivist learning, where students become researchers and independent thinkers. It will also be noted below that Caribbean students in Canada admonish their Canadian counterparts for 
making blanket observations without really having conducted any independent research.

\subsection{Analysis of incident 2}

In the second incident students are dismissing the fears of the Caribbean people in losing their culture through TV. Their comments are essentially that because these people are so poor, they should count themselves lucky that they even have TV. This incident illustrates the usefulness of the online discussion. The project only has access to this conversation between students because there was a trained researcher available to listen to these comments, but this is only rarely the case in classrooms. In fact, for the most part, the teacher may also be in another part of the room, when students come up with these racist and patronising comments. However, the second comment in the same incident was online and so captured, transparent and available for response, available for comment from other students, from experts of the culture and from students in Barbados too.

Thus we see that the third advantage of the Internet is that it provides transparency to people's comments. However, it also provides audience for more racist comments as discussed in the next section.

\subsection{Analysis of incident 3}

In this incident, a young student used the forum of the listserv to voice her impressions of her visit to the Caribbean. This student with her comments on the poverty, lack of education and dishonesty of the Caribbean peoples aroused a storm of protest from students outside her classroom.

The first response is from Keith's class, which has no students of Caribbean background, which is in fact only a few blocks away is:

"As far as I'm concerned, the comment from Island A is a disgrace. Your views on Caribbean culture are a disgrace and borderline racist. You are portraying the people of the Caribbean as lazy and having nothing better to do than 'rip-off' tourists."

Keith is pleasantly surprised; he has been working for months on getting his students to be less biased and here he sees them reacting to another student. This means that the Internet provides a forum for students to debate and discuss issues. Here we see an example of critical collaborative inquiry.

The second response is from two students who have just arrived from the Caribbean. They are new students in a class participating in the project. 
"I found these comments very biased and untrue. I have lived in the Caribbean and have never seen plastic tents on the beaches except for cub scout excursions. Education in most islands is free and many have high literacy rates and some higher than Canada. I want to know what island you visited because in all of the islands I have visited, I have not seen these conditions. Where are you learning all of this?

"Not since the Arawaks and Caribs (about the 15th century), have our people lived in huts and we only see them as a form of diversion for the tourists. Students should research the region before stating these false stereotypes that could influence people's decisions on visiting the islands."

The final response is from one of the Caribbean "experts", a professor from a nearby university who has volunteered to participate in this project, offering comments to students' online discussion.

"Some of you have raised the issue about 'ripping-off' tourists. Do some people in the Caribbean 'rip-off' tourists. Of course this happens! But it happens everywhere else in the world as well. Does this happen more in the Caribbean than in other parts of the world? No one really knows, but probably not. Quite often, however, the Caribbean is advertised to tourists in a very unrealistic way (is it paradise?) and this creates a problem for tourists when something 'wrong' happens. Does it rain in paradise? Maybe not. But it sure does in Jamaica."

This excerpt slowly but surely breaks down the stereotypes that the students have come up with, discussion must be based on issues and cannot be a simple listing of prejudice. Thus one student, through the power of a listserv receives three different types of responses. The first is from students who are of the same socio-economic background (and in fact from a school a few blocks away) as she is. The second is from students who come from the country of which she has such a low image. Finally, the third is from a reasoned and well-informed "expert" who is from the region she is speaking of. While it is difficult to gauge the long-term effect of this type of input to individual students, it is important to realise that this type of interaction was impossible until the technology broke down the traditional walls that existed between the classroom and the outside $=$ orld.

ICT also allowed the creation of an online inter-cultural communication, where each was provided equal access in the forum. This was a situation that was never available before; traditionally students relied on information from 
teachers and textbooks, sometimes from the library. Here they now had contact with the cultures they were studying.

But it must be made clear that it was not the technology, rather it was the careful setting up of the experience. Students were exposed to the highest quality materials, which were based upon research on issues, research on historical and present day political background. Students could not succeed unless they read the background literature. But if the outside world provided insights to students to cultures to which they did not have access before, the racism of the students within the classroom also reached the outside world.

It is interesting, however, that Janet, a teacher of Caribbean background who formed part of the simulation, posited that these views were very much part of the majority culture and that it was better that they were aired and dealt with in the safety of the classroom than if they were simply ignored and swept under the rug.

\section{FURTHER ANALYSIS}

In the Other Story project, researchers set up a learning network which promoted an opening up of communication between students of various cultures. While the technology provided an open and level playing field, each user being an equal node in a vast network, it was the narrow minded views and knowledge which portrayed the developing world in disparaging ways, which dominated the discourse.

At the beginning of this paper, two commercials were presented which portrayed the use of technology as neutral and in fact indispensable to global and universal happiness. In the course of the description of the simulation, it has been discovered that technology does not hide prejudice, it sometimes highlights it and renders it more transparent. ICT however also provides a way of opening up new avenues of communication.

It was demonstrated that there exists a deep psychological feeling of superiority over the developing world. In the next pages, an analysis of the larger context of the media that dominate the Western world is undertaken.

\subsection{THE CONTEXT OF INTER-CULTURAL UNDERSTANDING}

Mukherjee and Achebe have pointed out that while non-European cultures are regarded as "other", they are also often used as a backdrop to the playing out of the lives of the story's main characters, who are invariably white and of the dominant cultures. Thus we have Conrad's Heart of 
Darkness, where Africa serves as the primitive background of the struggle between civilisation and the jungle in the meaning making of the main character. This use of others, their land, their culture and their lives as just the backdrop to the sometimes meaningless romps of Hollywood actors and actresses is a tradition that continues today. It is portrayed in films like Out of Africa where the hauntingly beautiful African countryside becomes a romantic scene for the mating of two colonisers. The display of proud Africans who are masters of their own country and their own destiny as mere servants who cry and grovel in front of their white masters is ignored and arouses no comment. And as shown, it is precisely this unquestioning but demeaning and degenerating portrayal of the Other that comes through in classroom observations of students participating in the Other Story project.

While one may lament the level of awareness and lack of sophistication around issues of cultural imperialism and developing countries on the part of Canadian students, it does not seem surprising when one considers the diet of literature, films and TV programs that our culture feeds them continuously from birth. The Other Story project, however, provided Canadian students with an opportunity to see another perspective, that of the "other" whom they had considered voiceless until now.

While the Internet poses new opportunities for minorities to express themselves and to have a voice in the classroom, it is an achievement that can be marred because our students are not ready for this experience. The Other Story was saved from being a purely racist expression of student views because of the way it was constructed. Students were provided with high quality background materials, articles, films and stories written by the Caribbean people, and they had the presence of Caribbean students and "experts" available online to steer them away from problems.

Thus the Internet for inter-cultural understanding provides interactivity, transparency and equality, each of which can be abused unless we provide an experience that is carefully constructed, that reflects the views of the people we study. How then can we use the Internet in ways that will promote respect and communication between peoples of the world, a prerequisite for the future prosperity both economic and political of the globe?

\section{RECOMMENDATIONS}

As discussed above, it was the interactivity, transparency and equality provided by the technology which provided deeper and more intricate webs of meaning to inter-cultural understanding in the classroom. As such the following recommendations relate to each of these phenomena: 
Interactivity: Internet projects of the future which claim to promote intercultural understanding should ensure that there is interactivity between students of different backgrounds such that not only is each an equal node on the computer, but also that the learning experience which they undergo is not trivial or unexamined.

Transparency: Because ICT renders all communication transparent, it is vital that the teachers and organisers of the virtual conferences or any other form of communication between classrooms, ensure that an atmosphere of mutual respect and politeness pervade the discussions. On line privileges should be removed for all those who abuse this rule.

Equality: Because the Internet provides each with a node on the computer, it should not be assumed that classrooms across the globe have the same access, freedom of expression and even the bandwidth that Canadian students might enjoy. Internet projects should emphasise issues, discussions, even text based activities which then call upon other resources in the classroom environment rather than depending upon huge memory reserves with WWW-technologies. The emphasis should be on the egalitarian exchange of views, such that students may learn from and about each other.

Finally it is recommended that in opening up the classroom walls across geographical and national boundaries such that countries and cultures come together as equals, the following guidelines should be kept in mind:

a) Respect for all people of the world should be the basic premise and ground rule of all online discussions.

b) This respect can be engendered through a revision of all curricula, from textbooks, literature, documentaries and posters used in schools.

c) Ensure that traditional media which do not reflect this respect will be used to train students in developing critical analysis and humanistic views.

Students need to learn from a constructivist viewpoint. Classrooms are places where students might explore, analyse, question and challenge teachers on questions of cultural imperialism around the world. In classes where students are passive, awaiting the passing out of knowledge, untouched by discussion and questioning, the potential of the Net to teach others to understand people from their own perspectives becomes difficult.

While this simulation took place in the Canadian context, its recommendations are applicable to students in Westernised countries. It is important that students everywhere be exposed to a sympathetic but complex view of the developing world and this can best be achieved through direct contact possible through ICT technologies.

ICT offers a promise of allowing the "other" into the classroom as an equal. However the educational system has not done an adequate job of preparing students to be critical collaborative learners, thinking, questioning and learning. ICT can provide the circumstances which allow human beings 
to grow socially, ethically and intellectually but it is the teachers who need to bring the excitement and involvement back into the world of learning. Without having students as ethical, active, involved and intellectually challenged knowledge creators, there is no future for networked technologies except as vehicles of commerce or exotic travel.

\section{REFERENCES}

Cummins, J., and Sayers, D. (1995) Brave New Schools: Challenging Cultural Illiteracy through global learning networks, New York: St. Martin's Press.

Eurich-Fulcer, R. and Schofield, J. (1995) Wide-Area Networking in K-12 Education: Issues Shaping Implementation and Use, Computers Educ. 24 (3), 211-220.

Keating, D. (1995) The Transformation of schooling: Dealing with developmental diversity, Lupart, J., McKeough and Yewchuck, C. (Eds.), Schools in Transition: Rethinking Regular and Special Education, Toronto: Nelson, 119-139.

Mukherjee, A. (1988) Toward an Aesthetic of Opposition, Essays on Literature Criticism \& Cultural Imperialism. Toronto: Williams-Wallace Publishers.

Porter, M. (1994) A Second Media Age, ARENA Journal, no. 3, 49-91.

Riel, M. (1996) The Internet: A Land to Settle Rather Than an Ocean to Surf and a New "Place" for School Reform through Community Development, ISTE SIG/Tel Technology in Education Newsletter, Winter 1996 [http://www.gsn.org/teach/articles/netasplace.html].

Said, E. (1979) Orientalism, Vantage Books, New York: 1978.

Ungerleider, C. (1991) Media, Minorities and Misconceptions: The Portrayal by and Representation of Minorities in Canadian News Media, Canadian Ethnic Studies, XXIII (3), 158-163.

Warschauer, M. (2000) Technology and School Reform: A View from Both Sides of the Tracks" in Education Policy Analysis Archives, 8 (3), January 7, 2000, [http://epaa.asu.edu/epaa/v8n4.html].

Wells, G. (in press) Dialogue about Knowledge Building, Smith, B. (Ed.) Liberal Education in a Knowledge Society. La Salle: Open Court, [http://www.oise.on.ca/ gwells/ OpenCourt.html].

\section{BIOGRAPHY}

Alnaaz Kassam is a high school English teacher in Toronto, Canada. Her professional experience includes being a Senior Research Officer at the Ontario Institute for Studies in Education of the University of Toronto. She has worked with computers since 1983 in various capacities: training teachers in computer literacy, researching the first impact of computer technology in Ontario classrooms and using the Internet to link classrooms to promote inter-cultural understanding. She has been an English and computer literacy teacher for the past two years and has taught in the private and public school systems and at the elementary, secondary and adult levels. 